\title{
Analysis of some Factors Affecting Production Process of Rubber Seed Oil-based Biodiesel by Opinion Discrimination Analytical Modelling
}

\author{
${ }^{1}$ AKPAKA, PO; ${ }^{2}$ IGBOANUGO, AC; ${ }^{* 2}$ OMOTEHINSE, SA
}

\author{
${ }^{1}$ Rubber Research Institute of Nigeria, Iyanomo, P.M.B 1049, Benin City, Edo State, Nigeria \\ ${ }^{2}$ Department of Production Engineering, University of Benin, Benin City, Edo State, Nigeria \\ *Corresponding Author Email: drsamayodeji@ gmail.com; Tel: +234-803-597-1630 \\ Email: '1akpakaphilip@gmail.com, ${ }^{2}$ anthony.igboanugo@uniben.edu
}

\begin{abstract}
The concept of biodiesel viewed by pundits as a renewable alternative fuel to diesel engines that could partially or fully replace or reduce the use of petroleum diesel fuel has been gaining great importance worldwide for its good quality exhaust, sustainability and biodegradability. The irregularity in production output, low quality, wastes, and downtimes appears to be a serious production problem being faced by manufacturers of biodiesel products which this study seeks to address. This study seeks to analyze some factors affecting the production process of rubber seed oil based biodiesel using opinion discrimination analysis. The research entails the application of survey method to gather relevant information required to build appropriate data matrix of 31 factors that were used to craft questionnaire administered to 100 respondents for their expert evaluation. Rensis Likert's 5-point attitudinal scale was used in dimensioning the respondent's responses, which were recorded in descending order of rating and were captured in a 100 $\times 31$ data matrix and subsequently analyzed with the use of opinion discriminative analytical tool to obtain the discriminative powers (DP). The result of the DP-values obtained enabled us to appreciate the main factors that significantly influence the rubber seed oil based biodiesel production. In particular their relative influence is indicative of the magnitude of the DP-values. This study has revealed that the opinion discrimination analytical approach employed is effective in dealing with the problem of process variability and degraded output.
\end{abstract}

\section{DOI: https://dx.doi.org/10.4314/jasem.v23i1.25}

Copyright: Copyright $\odot 2019$ Akpaka et al. This is an open access article distributed under the Creative Commons Attribution License (CCL), which permits unrestricted use, distribution, and reproduction in any medium, provided the original work is properly cited.

Dates: Received: 01 January 2019; Revised: 27 January 2019; Accepted 30 January 2019

Keywords: Discriminative Power, Rubber Seed Oil, Opinion Discrimination Analysis, Rensis Likert

\begin{tabular}{ll}
\hline \multicolumn{2}{c}{ Nomenclature, Symbols and Notations } \\
\hline $\mathrm{R}=$ data matrix & $\in=$ element of \\
$\mathrm{i}^{\text {th }}=$ element of row & $\mathrm{j}^{\text {th }}=$ element of column \\
$\mathrm{a}_{\mathrm{ij}}=$ response of the respondents & $\leq=$ less than or equal to \\
$\forall=$ for all & $Q_{1} \ldots Q_{4}=$ quartile $1 \ldots . .4$ \\
$\mathrm{DP}=$ discriminative power & $\mathrm{WA}=$ weighted average \\
$\mathrm{r}_{i}=$ Rensis Likert's attitudinal rating & $\mathrm{f}_{i}=$ frequency of occurrence \\
Infimum = Greatest lower bound & Supremum = Least upper bound \\
$\sum=$ summation & $\subset=$ superset of \\
\hline
\end{tabular}

The concept of biodiesel seen by the pundits as a renewable alternate fuel to diesel engines that could be partially or fully replace or reduce the use of petroleum diesel fuel has been gaining great importance worldwide for its good quality exhaust, sustainability and biodegradability. Biodiesel as defined by Zhen-xing et al., (2013) is a monoalkyl esters of long chain fatty acids that originated from natural oils, fats of plants and animals and alcohols of lower molecular weights in the presence of catalysts and can be synthesized from edible and non-edible oils. Biodiesel is a kind of alternative for fossil fuels that has attracted wide attention in the world due to its renewability, biodegradability, nontoxicity and environmentally friendly benefits. Aransiola et al.,
(2014) described fossil fuels as non-renewable energy resources. Although, these fuels are contributing largely to the world energy supply, their production and use have raised environmental concerns and political debates. It has also been shown that $98 \%$ of carbon emissions are resulted from fossil fuel combustion. The world at present appears to be going through the worst energy crisis in history. This is due to the fact that a lot of countries are still heavily dependent on petroleum as their main source of energy. Demirbas (2009) noted that the only possible solution to this crisis is to find a sustainable (renewable) and economically feasible source of alternative energy. It was observed that there are many alternative energy sources such as wind, solar, 
geothermal and biomass that fulfill the first criterion (sustainability) while few of these can fulfill the second criterion which is economic feasibility. The best option, fulfilling both criteria identified is biofuel, particularly the one that is made from readily available biomass feedstock (Gui et al., 2008, Lam et al., 2009).

Considerable research efforts have been made by researchers in biodiesel production using different oils. Notable among them are: Yusuf et al., (2011) who reviewed the various methods for the production of biodiesel from vegetable oil, such as direct use and blending, micro-emulsion, pyrolysis and transesterification. Atadashi et al., (2010) reviewed the technologies used for the biodiesel separation and purification, biodiesel quality, and its effects on diesel engines. Biodiesel biodegradability, lubricity, stability, economic importance, and gaseous emissions were also discussed. Singh and Dipti (2010) reviewed the source of production and characterization of vegetable oils and their methyl ester as the substitute of the petroleum fuel and future possibilities of Biodiesel production. Ma et al., (1999) stated that Biodiesel has become more attractive recently because of its environmental benefits and fact that it is made from renewable resources. The raw materials being exploited commercially by the Biodiesel are the edible fatty oils derived from rapeseed, soybean, palm, sunflower, coconut, linseed, etc. (Ksorbitz, 1999). In recent years, research has been directed to explore plant based fuels, have bright future (Martini and Shell, 1998). The most commonly used oils for the production of Biodiesel are soybean (Freedman et al., 1986, Noureddini and Zhu, 1997), sunflower (Antolin et al., 2002, Mohamed et al., 2003), palm (Darnoko and Cheryan, 2000), rapeseed (Kusdiana and Saka, 2001), canola (Zou and Atkinson, 2003), cotton seed (Kose et al., 2002 and Jatropha (Foidl et al., 1996). Since the prices of edible vegetable oils are higher than that of diesel fuel, therefore waste vegetable oils and non-edible crude vegetable oils are preferred as potential low priced Biodiesel sources. According to Galadima et al., (2011) the Nigerian government has recently indicated commitment to biofuels production from local feedstock in order to reduce the country's over dependence on oil and gas economy and establish a strong link between the downstream petroleum industry and agricultural activities.

The opinion discrimination analysis modelling approach advocated in this study is predictive and innovative by nature in the sense that it foresees the imminence of process capability deterioration as well as the magnitude or degree of such dysfunction, and based on such information, adequate corrective action could then be taken. Literature reviewed has lucidly confirmed the versatility and applicability of opinion discrimination analytical modelling approach in detecting product failures generally. Examples include Igboanugo and Nwobi-Okoye (2012) and Adeleke et al., (2018). The samples surveyed so far also points to the fact that opinion discrimination analytical modelling approach is relevant in enhancing product quality, reduction of wastes, equipment and production system's management (Amiebenomo et al., 2013, Akpaka et al., 2018). The balance of literature on production system appears to offer little on opinion discrimination analytical modelling approach applications. Evidently, the current research is an attempt to create a breach in this knowledge frontier. The aim of this study therefore is to analyze some factors identified from relevant literature affecting the production process of rubber seed oil based biodiesel using opinion discrimination analytical modelling approach. This framework is believed to help deals with the associated problems that often occur during the production process of rubber seed oil based biodiesel.

\section{MATERIALS AND METHODS}

Research Design: The research method entails the application of survey method to gather relevant information required to build appropriate data matrix that are capable of causing a dysfunction in the manufacturing process of rubber seed oil based biodiesel. To achieve this end, extensive literature survey was carried out to articulate enough data. There were 31 variables (scale items) selected from the literature search to extensively cover factors causing manufacturing dysfunction in the production of rubber seed oil based biodiesel. The questions were carefully crafted to agitate curiosity of the respondents to respond positively to each of the 31 variables. Rensis Likert's 5-point attitudinal scale (5Strongly Agreed, 4-Agreed, 3-Undecided, 2Disagree, 1-Strongly disagree) was used in dimensioning the respondent's responses, which were recorded in descending order of rating and were captured in a $100 \times 31$ data matrix and subsequently analyzed with a statistical tool known as opinion discrimination analysis (ODA) to obtain the discriminative powers (DP). The DP values were plotted as bar chart as shown in figureland interpretations rendered. They are segmented as follows:

Lower bandwidth: $0<D P \leq 1.0$ : In this regime, the respondents are in total agreement on the issue considered. In other words there is consensuality. 
Middle bandwidth: $1.1<\mathrm{DP} \leq 2.0$ : In this group, the respondents are fairly in agreement on the subject matter.

Upper bandwidth: $2.1<\mathrm{DP} \leq 3.6$ : In this category, the respondents are controversial in agreement with what was put forth.

Models Employed: The Two distinctive models employed in this research work are: (i) Rensis Likert's 5-point attitudinal scale model and (ii) Discriminative Power Index.

Theoretical Framework: Consider a data matrix R constructed with a four point Rensis Likert's attitudinal scale comprising: Often (4), occasionally (3), rarely (2) and never (1). If "ij $01+$ is the element of $i^{\text {th }}$ row and $j^{\text {th }}$ column, where $a_{i j}$ is the response of the $\mathrm{i}^{\text {th }}$ respondent to $\mathrm{j}^{\text {th }}$ question crafted with the scale item and entries in $\mathrm{R}$ are recorded in descending order of $\mathrm{a}_{\mathrm{ij}}$, it follows that:

$a_{i j} \in \mathrm{R} a_{(i+1) j} \leq a_{i j} \forall_{j}$

Establish 4 quartiles of $\mathrm{R}$, namely: $Q_{1}, Q_{2}, Q_{3}$ and $Q_{4}$ where:

$Q_{1} \subset \mathrm{R}, 1=1,2, \ldots \ldots .4$

Discard $Q_{2}$ and $Q_{3}$ and use $Q_{1}$ and $Q_{4}$ to calculate discriminative power (DP)

DP calculations: let the weighted average WA be given by:

$W A=\frac{\sum_{1}^{4} r_{i} f_{i}}{\sum_{1}^{4} r_{i}}$

Where $r_{i}$ is the 4-points Rensis Likert's attitudinal rating and $\mathrm{f}_{i}$ is the frequency of occurrence of $\mathrm{r}_{i}$. Let $\mathrm{WA}_{1}$ be weighted average in quartile $1\left(Q_{1}\right)$ and $\mathrm{WA}_{2}$ be weighted average in quartile $4\left(Q_{4}\right)$. It follows that the DP is given by:

$\mathrm{DP}=\mathrm{WA}_{1}-\mathrm{WA}_{2}$

The theorems that underpin the foregoing discriminative power concept are briefly presented here.

Theorem 1: Let $\mathrm{R}$ represent reordered data matrix in merit order of respondent's scores. If all entries $a_{\mathrm{ij}} \in$ $\mathrm{R}$ are entirely uniform, the resulting $\mathrm{DP}=0$, leading to conclusiveness or consensually or complete agreement.

Proof: From Eq. (1) we have:

$W A=\frac{\sum_{1}^{4} r_{i} f_{i}}{\sum_{1}^{4} r_{i}}$
Let $\mathrm{WA}_{1}$ be weighted average in quartile $1\left(Q_{1}\right)$ and $\mathrm{WA}_{2}$ be weighted average in quartile $4\left(Q_{4}\right)$ :

Then $W A_{1}=\frac{\sum_{1}^{4} r_{1 i} f_{1 i}}{\sum_{1}^{4} r_{1 i}}$; also $W A_{2}=\frac{\sum_{1}^{4} r_{2 i} f_{2 i}}{\sum_{1}^{4} r_{2 i}}$.

Since, $r_{1 i}=r_{2 i}$ on account of uniform entries of $\mathrm{R}$, then $\mathrm{WA}_{1}-\mathrm{WA}_{2}=0$ (infimum).

Theorem 2: Let all elements of $Q_{1} \subset \mathrm{R}$ be 4 and those of $Q_{4} \subset \mathrm{R}$ be 1 . Then the resulting $\mathrm{DP}$ is a Supremum leading to controvertibility.

Proof: Let $a_{\mathrm{ij}} \in \mathrm{R}$ be uniform and consider $\mathrm{j}^{\text {th }}$ question. Also let $W_{1}$ be weighted average in quartile $1\left(Q_{1}\right)$ and $W_{2}$ be weigthed average in quartile $4\left(Q_{4}\right)$ :

Then $W A_{1}=\frac{\sum_{1}^{4} r_{1 i} f_{1 i}}{\sum_{1}^{4} r_{1 i}}$; also $W A_{2}=\frac{\sum_{1}^{4} r_{2 i} f_{2 i}}{\sum_{1}^{4} r_{2 i}}$.

Since $r_{1 i}=4 r_{2 i}$ on account of uniform entries of $\mathrm{R}$, then $\mathrm{WA}_{1}=\mathrm{WA}_{2}$. Therefore, $\mathrm{DP}=3 \mathrm{WA}_{2}$

Theorem 3: Let all elements of $Q_{1} \subset \mathrm{R}$ be $r_{1}$ and those of $Q_{4} \subset \mathrm{R}$ be $r_{2}$ where $r_{1}-r_{2}=1$. Then the resulting DP is a middling signifying inconclusiveness or is up in the air.

Proof: Let $\mathrm{WA}_{1}$ be weighted average in quartile 1 $\left(Q_{1}\right)$ and $\mathrm{WA}_{2}$ be weighted average in quartile $4\left(Q_{4}\right)$

Then $W A_{1}=\frac{\sum_{1}^{4} r_{1 i} f_{1 i}}{\sum_{1}^{4} r_{1 i}}$ also $W A_{2}=\frac{\sum_{1}^{4} r_{2 i} f_{2 i}}{\sum_{1}^{4} r_{2 i}}$ since, $\mathrm{f}_{1 \mathrm{i}}=\mathrm{f}_{2 \mathrm{i}}$ and $\mathrm{r}_{1 \mathrm{i}}-\mathrm{r}_{2 \mathrm{i}}=1$ then,

$\mathrm{WA}_{2}-\mathrm{WA}_{2}=\frac{\sum_{1}^{4} \mathrm{f}_{1 \mathrm{i}}\left(r_{1 i}-r_{2 i)}\right.}{\sum_{1}^{4} \mathrm{f}_{1 i}}=1$

Representation of the DP Profile: A presentation of the DP values on a bar chart can be seen in Figure 1, this highlights the DP values as bars.

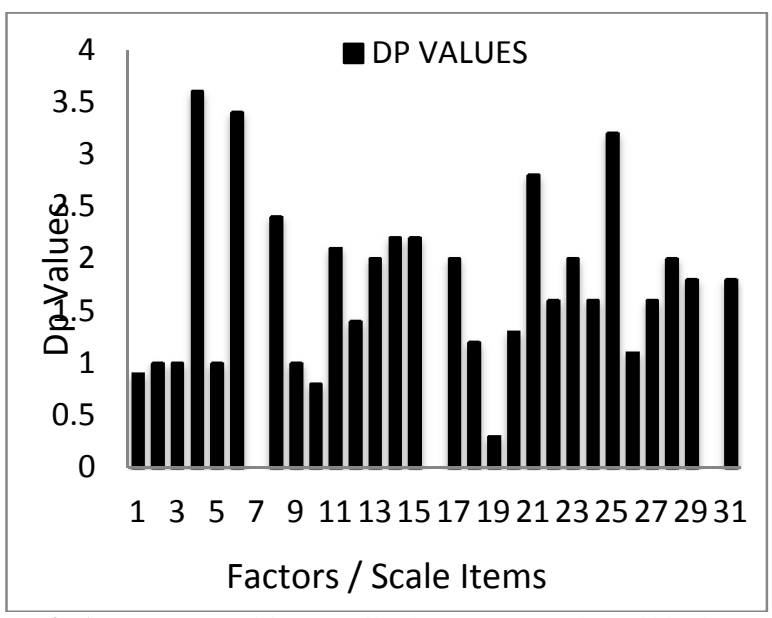

Fig 1: DP Values of factors affecting the production of biodiesel 


\section{RESULTS AND DISCUSSION}

The DP-values are segmented as follows: Lower bandwidth: $0<D P \leq 1.0$ : In this regime, the respondents are in total agreement on the issue considered. In other words there is consensuality.

Table 1: Lower bandwidth DP values of variables that affect the

\begin{tabular}{lll}
\multicolumn{2}{c}{ production of rubber seed oil based biodiesel } \\
\hline $\begin{array}{l}\text { Variable } \\
\text { Number }\end{array}$ & Description & $\begin{array}{l}\text { DP } \\
\text { Value }\end{array}$ \\
\hline 1 & Reaction time & 0.9 \\
2 & Reaction Temperature & 1.0 \\
3 & Agitation speed & 1.0 \\
5 & Transesterification & 1.0 \\
7 & Mixing Intensity & 0 \\
9 & Alcohol molar ratio & 1.0 \\
10 & Purity of reactants & 0.8 \\
16 & Kinematic viscosity & 0 \\
19 & Amount of reagents & 0.3 \\
30 & Moisture level & 0 \\
\hline
\end{tabular}

It was observed in Table 1 above that the DP Values were very low indicating that there is high level of agreement among respondents that these variables significantly affect the production of rubber seed oil based biodiesel. The respondents' views were in total agreement on the attributions raised on reaction temperature effect on the yield of biodiesel. They agreed that higher reaction temperature increases the reaction rate and shortened the reaction time due to the reduction in viscosity of the vegetable oils. They also agreed that the transesterification reaction temperature should be below the boiling point of the alcohol used in order to prevent the alcohol evaporation. The respondents also agreed that agitation speed plays an important role in the formation of end product of biodiesel because agitation of oil and catalyst mixture is what enhances the reaction. They agreed that the higher the speed of agitation or stirring, the higher the yield of biodiesel produced and lower stirring speed result in lower biodiesel product formation. Thus the respondent's responses were in harmony with all opinion hence the low DP value. On transesterification, the respondents acclaimed that the use of neat vegetable oils in engines was possible, with some minor modifications in the fuel system. They affirmed that in long-term operation, vegetable oils could cause gum development because of their high viscosity. Other difficulties that were highlighted with the use of vegetable oils include formation of injector deposits, ring sticking etc. Solution to the problem of high viscosity of vegetable oils had been approached by using the method of transesterification. The respondents said transesterification is the best method among other approaches due to its low cost and simplicity. This process was the common way to produce biodiesel from vegetable oils. They said that transesterification process helped to reduce the viscosity of the oil making it applicable as fuel in compression ignition diesel engines. Respondent views on mixing intensity were unanimous. They opined that oils and alcohols which were the reactants used for biodiesel production was not totally miscible. So they posited that mixing was very important in the transesterification process to promote contact between these two feed stocks to ensure good and uniform mixing resulting in good quality diesel. Respondent views on oil molar ratio were congruent. They said that oil molar ratio refers to the average molecular weight of oil in the transesterification reaction for the production of biodiesel. They were undivided on the issue raised and said it could affect the conversion efficiency leading to good quality yield of biodiesel.

The respondents were also unanimous and consistent in their decisions on the effect of kinematic viscosity, amount of reagents, moisture level as well as purity of reactants in biodiesel production.

Middle bandwidth: $1.1<\mathrm{DP} \leq 2.0$ : In this group, the respondents are fairly in agreement on the subject matter.

Table 2: Middle bandwidth DP values of variables that affect the production of rubber seed oil based biodiesel.

\begin{tabular}{lll}
\hline $\begin{array}{l}\text { Variable } \\
\text { Number }\end{array}$ & Description & $\begin{array}{l}\text { DP } \\
\text { Value }\end{array}$ \\
\hline 12 & Physicochemical properties & 1.4 \\
13 & Thermal cracking (Pyrolysis) & 2.0 \\
17 & Oxidative stability & 2.0 \\
18 & Induction time & 1.2 \\
20 & Type of reagents & 1.3 \\
22 & Oil price & 1.6 \\
23 & Reaction rate & 2.0 \\
24 & Oil availability & 1.6 \\
26 & Storage time & 1.1 \\
27 & Oil type & 1.6 \\
28 & Production method & 2.0 \\
29 & Storage conditions & 1.8 \\
31 & Order of reaction & 1.8 \\
\hline
\end{tabular}

In table 2 shown above, the respondents are fairly in agreement with certain attributions made concerning these variables. The decisions reached about this cluster are therefore considered fairly conclusive. We can say that the DP value resulting is middling; signify inconclusiveness or middle of the road difference. The reason for this is evident in Theorem 3. The respondent views under this regime were open to doubt on the physicochemical properties, type of reagents, production method, reaction rate, order of reaction as well as storage conditions effect on biodiesel production. Their responses concerning the issues raised were debatable hence the middling DP value. 
Upper bandwidth: $2.1<\mathrm{DP} \leq 3.6$ : In this category, the respondents are controversial in agreement with what was put forth.

Table 3: Upper bandwidth DP values of variables that affect the

\begin{tabular}{lll}
\multicolumn{2}{l}{ production of rubber seed oil based biodiesel } \\
\hline $\begin{array}{l}\text { Variable } \\
\text { Number }\end{array}$ & Description & $\begin{array}{l}\text { DP } \\
\text { Value }\end{array}$ \\
\hline 4 & & 3.6 \\
6 & Catalyst concentration & 3.4 \\
8 & Type of catalyst & 2.4 \\
11 & Oil molar ratio & 2.1 \\
14 & Moisture content & 2.2 \\
15 & Free fatty acid & 2.2 \\
21 & Density & 2.8 \\
& Environmental & \\
25 & conditions & 3.2 \\
\hline
\end{tabular}

Under this regime as shown in table 3 the DP values are high. The variables clustered therein are relatively controversial. This is because the respondents were weakly in agreement with the attributions made concerning the variables that clustered in this regime. This however showed a case of controvertibility and the reason for this is discussed in Theorem 2 . Respondents under this cluster share diverse views on catalyst concentration, type of catalyst, oil molar ratio, free fatty acid, density, geographical location and moisture content as they affect the production of biodiesel. While some argue about the variables having a significant influence on the biodiesel, others have a divergent view on the same matter. At the onset it was claimed that opinion discrimination analytical modelling tool can deal with the problem capable of causing a dysfunction in the production process of rubber seed oil based biodiesel. The DPvalues obtained during this research have enabled us to appreciate the main factors to blame for the manufacturing dysfunction in biodiesel production. In particular, their relative influence is indicative of the magnitude of the DP-values. This is also a manager's guide to action.

Conclusion: The result obtained from this study shows that the opinion discrimination analytical tool employed using DP-values, has been helpful in dealing with manufacturing dysfunction in the production process of rubber seed oil based biodiesel common in small and medium scale enterprises especially in developing countries where manufacturing functions are stymied by economic depression. Investigation made through this study also revealed that it takes a substantial amount of insight, ability, and experience to establish individual and collective actions of factors that influence rubber seed oil based alkyd resin production process. Again, the modelling approach employed had been shown to possess inherent properties for predicting imminence of process capability deterioration. Finally, the theory underpinning the discriminative power index is also developed and demonstrated.

\section{REFERENCES}

Adeleke, TB; Ukwuaba, SI; Akpaka, PO (2018). Modelling tool for solving manufacturing system dysfunction in rubber seed oil based alkyd resin preparation. Nig. J. Technol. 37(3): 692-695.

Akpaka, PO; Igboanugo, AC; Omotehinse, SA; Fagbemi, EA (2018). Opinion discrimination analysis of factors affecting the manufacturing process of rubber seed oil based alkyd resin. World J. Engineer. Res. Technol. 4, (5) 410421.

Amiebenomo, SO; Omorodion, II; Igbinoba, JO (2013). Development of Generic Checklist for Diesel Power Generator Maintenance. Int. J. Applied Sci. Engineer. Res. 2(3): 270-280.

Antolı’n, G; Tinaut, FV; Briceño, Y; Castaño, V; $\mathrm{Pe}^{\prime}$ rez, C; Ramı́rez, AI (2002). Optimization of Biodiesel production by sunflower oil transesterification. Bioresour Technol. 83(2):111-4.

Aransiola, EF; Betiku, E; Ikhuomoregbe, DIO; Ojumu, TV (2012). Production of biodiesel from crude neem oil feedstock and its emissions from internal combustion engines. Afri. J. Biotechnol.11 (22): 6178-6186.

Atadashi, IM; Aroua, MK; AbdulAziz, A (2010). High quality biodiesel and its diesel engine application: A review. Renewable Sustainable Energy Rev. 14: 1999-2008.

Darnoko, D; Cheryan, M (2000). Kinetics of palm oil transesterification in a batch reactor. $\mathrm{J} \mathrm{Am} \mathrm{Oil}$ Chem. Soc. 77(12):1263-7.

Demirbas, A (2009). Progress and recent trends in biodiesel fuels. Energy Convers Manage. 50:14- 34 .

Foidl, N; Foidl, G; Sanchez, M; Mittelbach, M; Hackel, S (1996). Jatropha curcas L. as a source for the production of biofuel in Nicaragua. Bioresour Technol. 58:77-82.

Freedman, B; Butterfield, RO; Pryde, EH (1986). Transesterification kinetics of soybean oil. J Am Oil Chem. Soc. 63(10):1375-80. 
Galadima, A; Garba, ZN; Ibrahim, BM; Almustapha, MN; Leke, L; Adam, IK (2011). Biofuels Production in Nigeria: The Policy and Public Opinions. J. Sustainable Develop. 4. (4) 22-31.

Gui, MM; Lee, KT (2008). Bhatia S. Feasibility of edible oil vs. waste edible oil as biodiesel feedstock. Energy. 33:1646-53.

Igboanugo, AC; Nwobi-Okoye, CC (2012). Transfer function modelling as a tool for solving manufacturing system dysfunction. Res. J. Appl. Sci. Engineer. Technol. 4(23): 49484953.

Kose, O; Tuter, M; Aksoy, HA (2002). Immobilized Candida antarctica lipase-catalyzed alcoholysis of cotton seed oil in a solvent-free medium. Bioresour Technol. 83:125-9.

Ksorbitz, W (1999). Biodiesel production in Europe and North American, an encouraging prospect. Renew Energy. 16:1078-83.

Kusdiana, Daa; Saka, S (2001). Kinetics of transestrification in rapseed oil to biodiesel fuel as tested in supercritical methanol. Fuel. 80:693-5.

Lam, MK, Tan KT, Lee KT, Mohamed AR. (2009). Malaysian palm oil: surviving the food versus fuel dispute for a sustainable future. Renew Sustain Energy. 13:1456-64.

Ma, F; Clement, LD; Hanna, MA (1999). The effect of mixing on transesterification of beef tallow. Bioresour Technol. 69:289-93.
Martini, N; Shell JS (1998). Plant oils as fuelspresent state of science and future development. Berlin: Spinger; p. 276.

Mohamed, M; Soumanoua, B; Uwe, T; Bornscheuer, A (2003). Improvement in lipasecatalyzed synthesis of fatty acid methyl esters from sunflower oil. Enzyme Microb Technol. 33:97103.

Noureddini, H; Zhu, D (1997). Kinetics of transesterification of soybean oil. $J$ Am Oil Chem. Soc. 74:1457-63.

Singh, SP; Singh Dipti (2010). Biodiesel production through the use of different sources and characterization of oils and their esters as the substitute of diesel: A review. Renewable and Sustainable Energy Reviews 14: 200-216.

Yusuf, NNAN, Kamarudin, SK; Yaakub, Z (2011). Overview on the current trends in biodiesel production. Energy Conversion. Manage. 52: 2741-2751.

Zhen-xing, L; Xiao-an, N; Yi-gang, W (2013). Study on Technology of Comprehensive Utilization of Biodiesel and Dimers from Rapeseed Oil. J. Forest Prod. Ind. 2(4): 5-8.

Zou, L; Atkinson S (2003). Characterizing vehicle emissions from the burning of biodiesel made from vegetable oil. Environ Technol. 24:1253. 